\title{
Effect of tilting angle on natural convection heat transfer from a cylinder suspended in stagnant water
}

\section{Hesham Elbakhshawangy}

Reactors department, Nuclear Research Center, Atomic Energy Authority, Cairo, Egypt

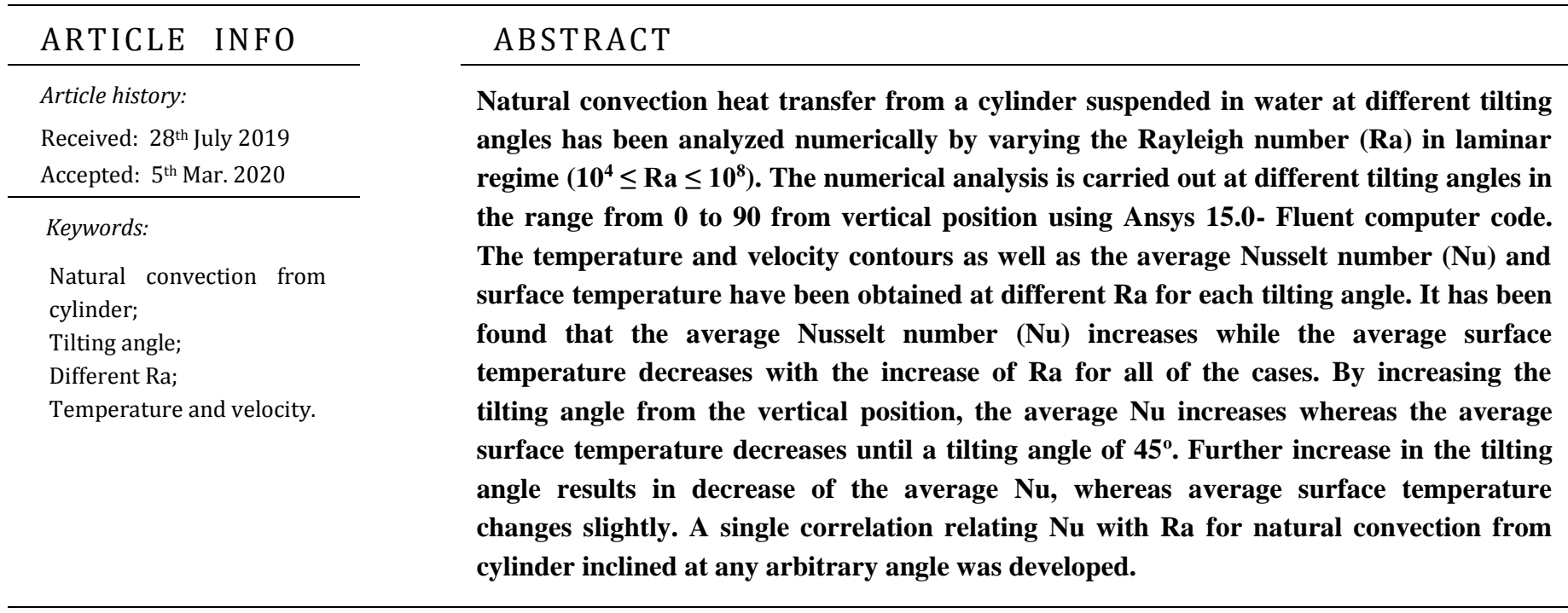

\section{Nomenclature:}

At

D

$\mathrm{Gr}$

$\mathrm{g}$

$\mathrm{h}$

k

$\mathrm{L}$

$\mathrm{m}$.

$\mathrm{Nu}$

$\mathrm{Nu}^{*}$

$\operatorname{Pr}$

$P$

Q

$\mathrm{Ra}$

$\mathrm{R}$

$\mathrm{Ra}^{*}$

$\mathrm{r}$

$\mathrm{T}$

Tw

$\mathrm{Tb}$

$\mathrm{t}$

$V_{X}, V_{Y}, V_{Z}$ total area of convective surface, $\mathrm{m}^{2}$

diameter of the cylinder, $\mathrm{m}$

Grashof number, $g \beta \Delta T L^{3} / v^{2}$

gravitational acceleration, $\mathrm{m} / \mathrm{s}^{2}$

average convective heat transfer coefficient, $\mathrm{W} / \mathrm{m}^{2} \mathrm{k}$

thermal conductivity of fluid, $\mathrm{W} / \mathrm{mK}$

length of the cylinder, $\mathrm{m}$

mass flow rate, $(\mathrm{kg} / \mathrm{sec})$

average surface Nusselt number

Nusselt number based on $\mathrm{L}_{\mathrm{c}}$ (section 5.3)

Prandtl number

pressure, $\mathrm{N} / \mathrm{m}^{2}$

total heat transfer rate, $\mathrm{W}$

Rayleigh number

radius of the cylinder, $\mathrm{m}$

Rayleigh number based on $\mathrm{L}_{\mathrm{c}}$

radial coordinate

fluid temperature, $\mathrm{K}$

cylinder surface temperature, $\mathrm{K}$

bulk temperature, $\mathrm{K}$

time, sec

velocity components, $\mathrm{m} / \mathrm{s}$ 


\section{Greek Symbols:}

\section{B}

$\alpha$

v

$\rho$

$\mu$ thermal expansion coefficient, $1 / \mathrm{K}$

thermal diffusivity, $\mathrm{m}^{2} / \mathrm{s}$

kinematic viscosity, $\mathrm{m}^{2} / \mathrm{s}$

density, $\mathrm{kg} / \mathrm{m}^{3}$

dynamic viscosity, $\mathrm{kg} / \mathrm{ms}$

\section{INTRODUCTION}

Heat transfer by natural convection is involved in many practical situations as it has many advantages. Some of these advantages are less noise, less coast, and it does not need maintenance as it does not involve moving parts. Among the practical situations in which natural convection is involved, is natural convection from heated cylinders. Heat transfer by natural convection from cylinders is found in many practical situations such as using hollow cylinders in medical operations where it is placed around light sources. In these cases, the cylinder is heated up and then cooled by natural convection in ambient air. Natural convection from cylinders is found also in steel industries where vertical cylinders are sometimes suspended in air for immediate cooling. One of the most important practical situations in which natural convection from cylinders are encountered is in research reactors where the process of radioisotope production is performed by placing the targets to be irradiated in a cylindrical can, and heat is generated from these targets due to irradiation. Cooling of this can is usually achieved by forced convection of water. Safety analysis of these irradiation processes requires that the calculation is done in a conservative way, assuming heat removal by natural convection in stagnant water. Many researches on heat transfer by natural convection from cylinders have been conducted. Swastik Acharya et.al [1] studied numerically heat transfer by natural convection from a vertical hollow cylinder suspended in ambient air by varying the Rayleigh number $(\mathrm{Ra})$ in the laminar region $\left(10^{4} \leq \mathrm{Ra} \leq\right.$ $10^{8}$ ). They studied the effect of the ratio of length to pipe diameter (L/D) by varying it in the range $0.05 \leq \mathrm{L} / \mathrm{D} \leq$ 20. They demonstrated that in all the cases of L/D, the average $\mathrm{Nu}$ for both the outer and the inner surface of the cylinder increases as the Ra increases. The Nusselt number $(\mathrm{Nu})$ of the outer surface of a hollow cylinder exactly matches with that of the solid cylinder for all $\mathrm{L} / \mathrm{D}$ when Ra is less than $10^{6}$ but for a Ra beyond $10^{6}$ the $\mathrm{Nu}$ of the outer surface of the hollow cylinder is marginally higher than that of the solid cylinder. Churchill and Chu [2] and Churchill [3], experimentally

studied the natural convection from a horizontal cylinder and vertical flat plate respectively. They reported a correlation for average $\mathrm{Nu}$ as a function of Prandtl number (Pr) and Ra. The effect of curvature and the criteria for a vertical cylinder to be treated as a vertical flat plate have been studied by some researchers as given by Gebhart et al.[4] and explained in Ozisik [5] and Holman [6]. LeFevre and Ede [7] proposed a solution that accounts for the effect of wall curvature in the laminar range. Fujji and Uehara [8] compared the heat transfer rate for the case of laminar natural convection from a vertical cylinder with that from a vertical flat plate. Acharya and Dash $[9,10]$ studied numerically the natural convection heat transfer from an isothermal horizontal hollow cylinder with and without perforation. They showed the flow and thermal contours around the cylinder and proposed a correlation for the value of $\mathrm{Nu}$. In addition to numerical studies, also many experimental studies have been performed during the last three decades and interesting results have been presented. L. Davidson et.al [11] studied the natural convection phenomenon in vertical shell and tube. They studied the effect of different inlet conditions and geometrical dimensions on the developed thermal and velocity boundary layers. They showed that the larger the inlet velocity, the larger the $\mathrm{Nu}$ especially near the transition region where the variation in $\mathrm{Nu}$ is large. Whereas, this variation in $\mathrm{Nu}$ gradually vanishes in the fully turbulent region. Crane [12] discussed how, high Pr affect free convection through vertical cylinder. C.O.Popiel [13] studied the effect of curvature of the cylinder boundary layer thickness when it is comparable with the diameter of the cylinder. Modified integral method is used for boundary layer calculations. Shiri et.al [14] studied experimentally the natural convection in the near wall region of vertical cylinder. They measured the mean and turbulence quantities in the near wall region, where there is considerable variation of thermal properties due to high temperature gradient there. A new set of boundary layer equations are established to represent the variable properties of the flow in this region. In this paper natural convection heat transfer from a cylinder suspended in 
water at different tilting angles, from the vertical position, has been analyzed numerically by varying the $\mathrm{Ra}$ in laminar regime $\left(10^{4} \leq \mathrm{Ra} \leq 10^{8}\right)$. The cylinder under study is a solid cylinder of $2.5 \mathrm{~cm}$ diameter and $8 \mathrm{~cm}$ length with a constant heat generation of $250000 \mathrm{~W}$. This cylinder simulates the can used for isotope production in ETRR-2, whereas different targets are placed inside this can during irradiation.

\section{Problem description}

Fig. (1.a) shows isometric view of the studied geometry where half of the solid cylinder surrounded by stagnant water is simulated because of symmetry of the problem, while Fig (1.b) shows 2D view of the computational domain with boundary conditions to be used in the numerical computations. The cylinder under study is of $2.5 \mathrm{~cm}$ in diameter and $8 \mathrm{~cm}$ in length. Ansys Fluent release 15 computer code is used for carrying out the numerical simulation of the problem. The dimensions shown in Fig (1.b) are derived by carrying out domain independent tests which show that the most effective dimension is the distance between the top of the cylinder and top end of the computational domain as reported by Swastik Acharya et.al [1]. Whereas the distance between the bottom of the cylinder and the bottom of the domain and the distance from the side surfaces of the cylinder to the side surfaces of the domain do not influence the result at all.

a)

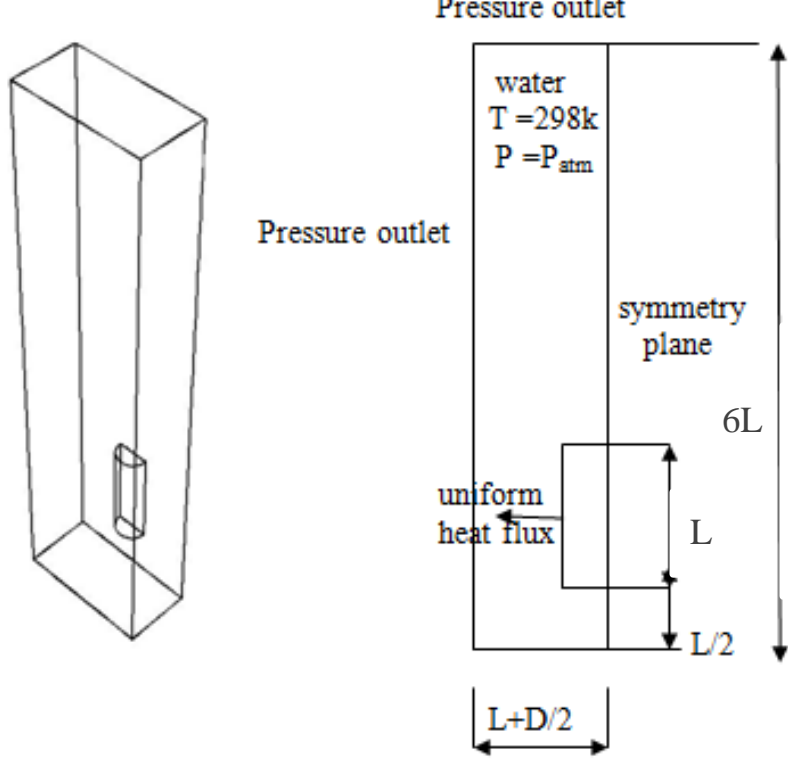

Fig. (1). a) 3D view of cylinder suspended in stagnant water

b) Dimensions of the computational domain

\section{METHODOLOGY}

3D steady laminar flow around cylinder in stagnant water is simulated at different tilting angles from the vertical position. The mathematical model for this simulation is shown below:

$$
\begin{aligned}
& \frac{\partial u}{\partial x}+\frac{\partial v}{\partial y}+\frac{\partial w}{\partial z}=0 \\
& w \frac{\partial u}{\partial z}+u \frac{\partial u}{\partial x}+v \frac{\partial u}{\partial y}=-\frac{1}{\rho} \frac{\partial p}{\partial x}+\frac{\mu}{\rho}\left(\frac{\partial^{2} u}{\partial x^{2}}+\frac{\partial^{2} u}{\partial y^{2}}+\frac{\partial^{2} u}{\partial z^{2}}\right)
\end{aligned}
$$

(x momentum)

$$
w \frac{\partial w}{\partial z}+u \frac{\partial w}{\partial x}+v \frac{\partial w}{\partial y}=-\frac{1}{\rho} \frac{\partial p}{\partial z}+\frac{\mu}{\rho}\left(\frac{\partial^{2} w}{\partial x^{2}}+\frac{\partial^{2} w}{\partial y^{2}}+\frac{\partial^{2} w}{\partial z^{2}}\right)+g \beta\left(T-T_{o}\right)
$$

(y momentum)

$$
w \frac{\partial v}{\partial z}+u \frac{\partial v}{\partial x}+v \frac{\partial v}{\partial y}=-\frac{1}{\rho} \frac{\partial p}{\partial y}+\frac{\mu}{\rho}\left(\frac{\partial^{2} v}{\partial x^{2}}+\frac{\partial^{2} v}{\partial y^{2}}+\frac{\partial^{2} v}{\partial z^{2}}\right)
$$

(z momentum)

$$
\rho C_{p}\left(w \frac{\partial T}{\partial z}+u \frac{\partial T}{\partial x}+v \frac{\partial T}{\partial y}\right)=k\left(\frac{\partial^{2} T}{\partial x^{2}}+\frac{\partial^{2} T}{\partial y^{2}}+\frac{\partial^{2} T}{\partial z^{2}}\right)+Q
$$

(energy)

Boussinesq approximation is included in the $\mathrm{Y}$ momentum equation to account for the natural convection. In the term of buoyancy, the reference temperature corresponds to the bulk fluid temperature and is fixed at $298 \mathrm{~K}$. Hence temperature difference between the wall and bulk fluid is relatively small throughout all of the runs and the Boussinesq approximation remains valid. With respect to the boundary conditions, constant heat generation of 250000 $\mathrm{W} / \mathrm{m}^{3}$ is applied inside the can throughout all of the runs. Constant value for the pressure corresponds to atmospheric pressure value is applied at all of the water boundary except the right plane shown in Fig.1 which is the symmetry plane. The set of differential equations are discretized using the finite volume technique to obtain a set of algebraic equations. The resulting equations are solved numerically using Ansys-Fluent version 15. The number of elements used for numerical analysis is 126600. Greater number of elements does not affect the solution. For each value of $\mathrm{Ra}$, and tilting angle, the temperature and velocity contours as well as the average value of $\mathrm{Nu}$ are deduced.

$\mathrm{Nu}=\mathrm{hL} / \mathrm{k}$

$\mathrm{Q}=\mathrm{hA}\left(\mathrm{T}_{\mathrm{w}}-\mathrm{T}_{\mathrm{b}}\right)$

$\mathrm{A}=2 \Pi \mathrm{d} \mathrm{l}$

$\mathrm{T}_{\mathrm{w}}$ is calculated by Ansys Fluent computer code. 


\section{VALIDATION}

Figure 2 shows the variation of the average $\mathrm{Nu}$ with $\mathrm{Ra}$ for the case of vertical cylinder. The results that were obtained from the present study are compared with the correlation of Churchil [3] which is:

$$
\mathrm{Nu}=\mathrm{F}\left[0.825+0.387(\mathrm{GrPr})^{1 / 6} /\left\{1+(0.492 / \mathrm{Pr})^{9 / 16}\right\}^{8 / 27}\right]^{2}
$$

In this correlation $\mathrm{F}$ is a correction factor accounts for the curvature effect since the correlation of Churchil is for flat plat and can be used for the case of cylinder in provided that $\mathrm{D} / \mathrm{L} \geq 35 /\left(\mathrm{Gr}^{1 / 4}\right)$. The correction factor $\mathrm{F}$ was proposed by Minkowycz and
Sparrow [15] for gases with Prandtl number $\operatorname{Pr}=0.7$, where

$$
\mathrm{F}=1.3\left[\frac{L}{\frac{D}{G r_{D}}}\right]^{0.25}+1
$$

Figure 2 shows that the results obtained from the present study are in a good agreement with the correlation of Churchil. From this comparison for the case of vertical cylinder, we can proceed to simulate numerically the case of natural convection at different angles with respect to the vertical position of the cylinder and with the same grid size and domain dimensions.

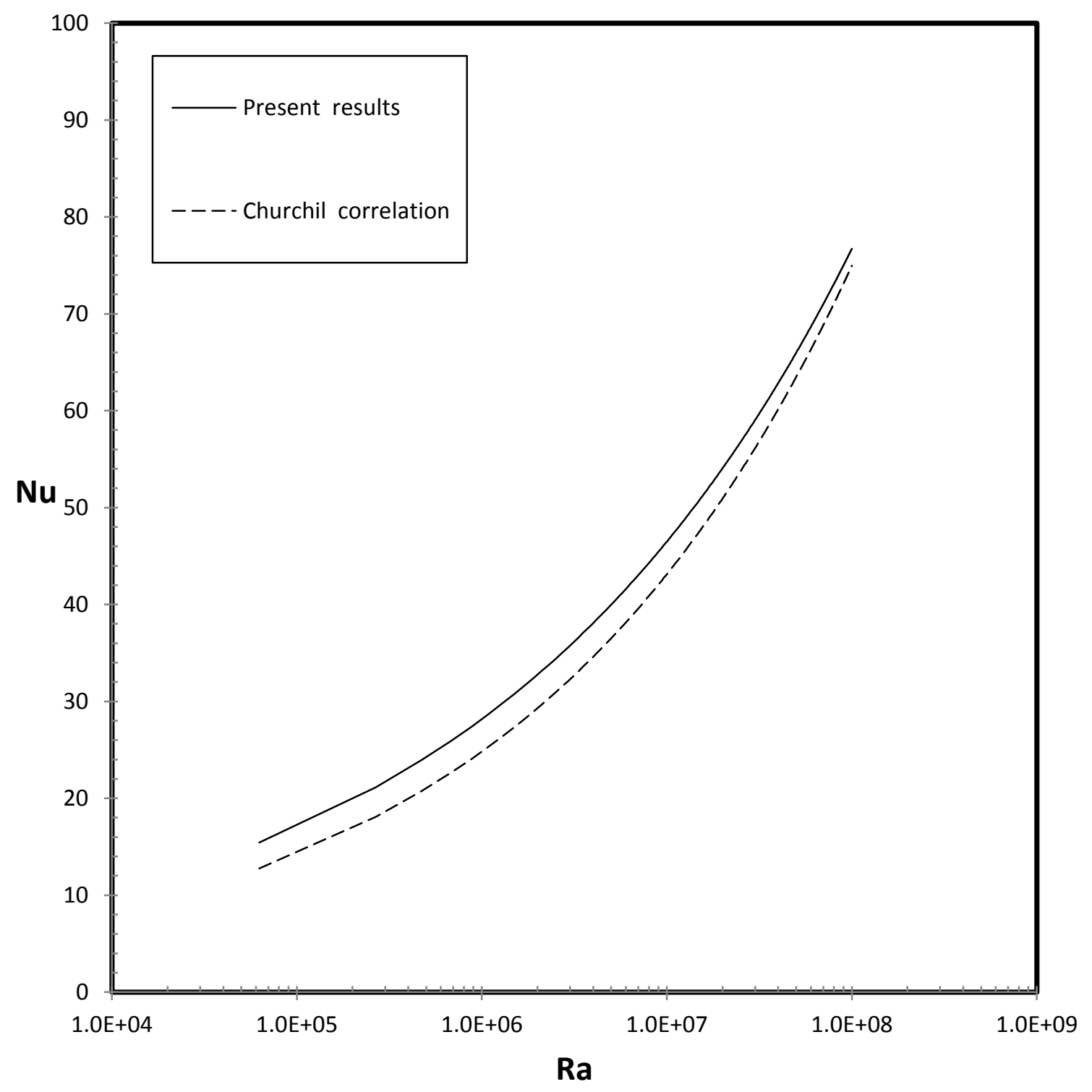

Fig. (2): variation of the average $\mathrm{Nu}$ with $\mathrm{Ra}$ for the case of vertical cylinder 


\section{RESULTS AND DISCUSSION}

\subsection{Effect of Ra}
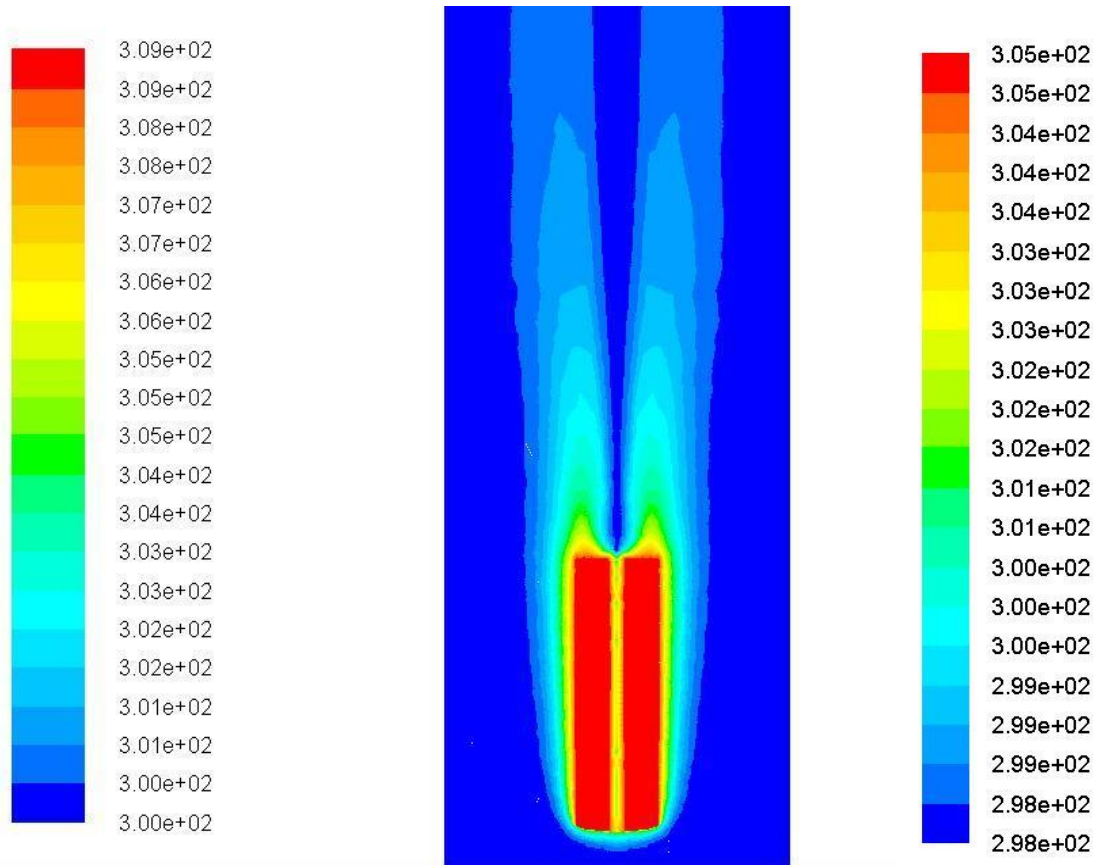

$$
\mathbf{R a}=6 \times 10^{4}
$$

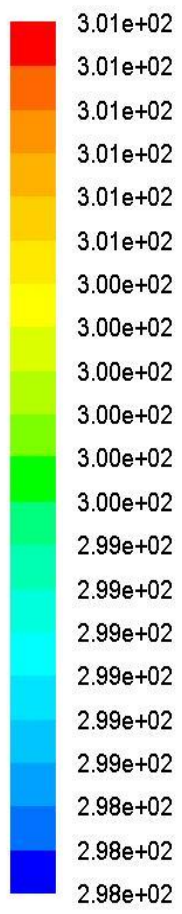

$3.03 \mathrm{e}+02$

$3.03 e+02$

$3.03 e+02$

$3.02 \mathrm{e}+02$

$3.02 e+02$

$3.02 \mathrm{e}+02$

$3.02 \mathrm{e}+02$

$3.01 e+02$

$3.01 e+02$

$3.01 e+02$

$3.01 \mathrm{e}+02$

$3.00 \mathrm{e}+02$

$3.00 \mathrm{e}+02$

$3.00 e+02$

$3.00 e+02$

$2.99 \mathrm{e}+02$

$2.99 e+02$

$2.99 \mathrm{e}+02$

$2.99 \mathrm{e}+02$

$2.98 \mathrm{e}+02$

$2.98 \mathrm{e}+02$

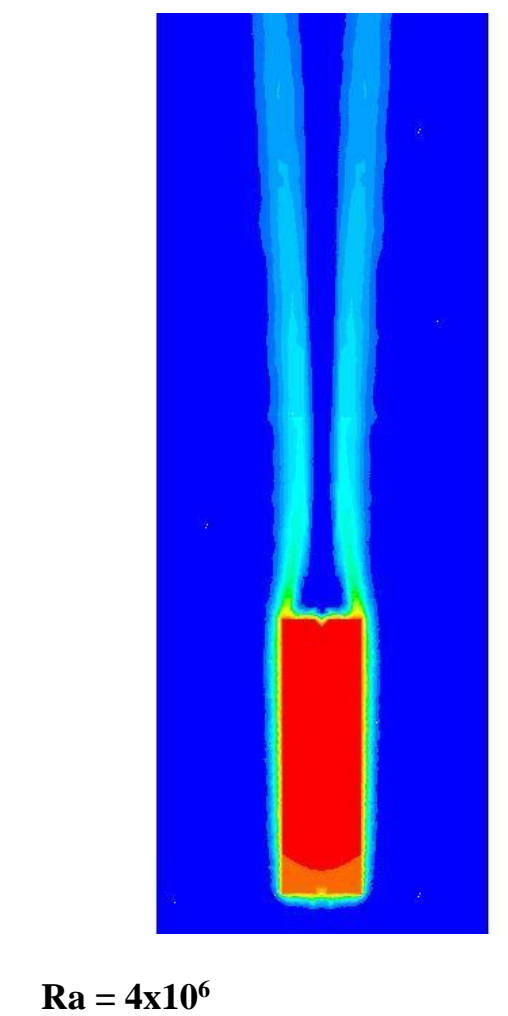

$\operatorname{Ra}=4 \times 10^{6}$

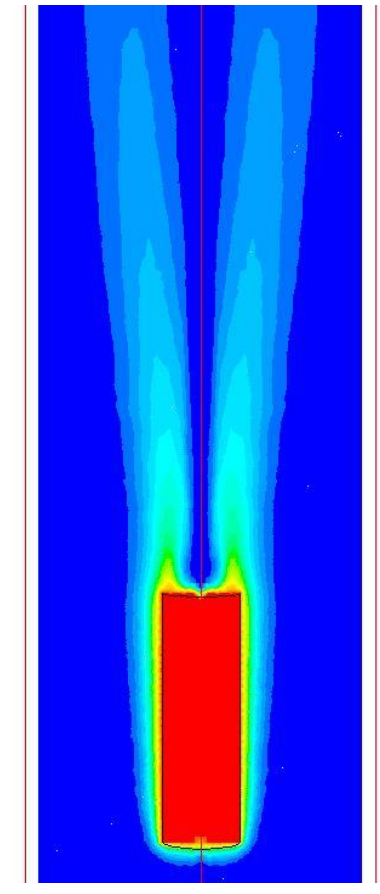

$\mathbf{R a}=5 \times 10^{5}$

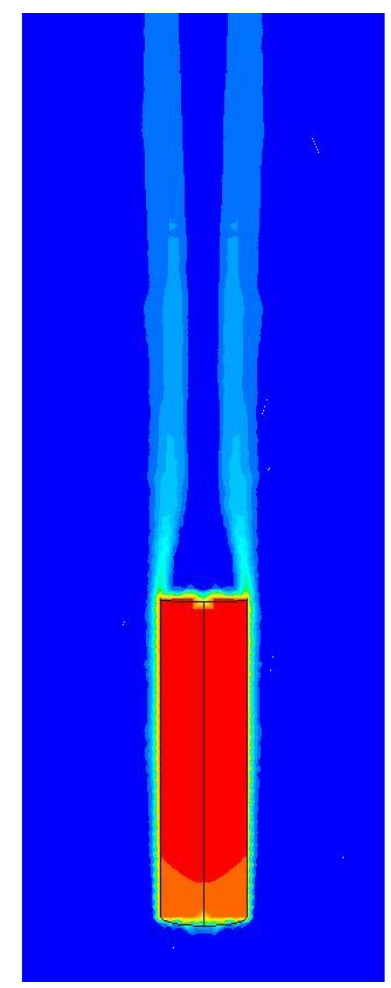

$\mathbf{R a}=3 \times \mathbf{x 1 0}^{7}$ 

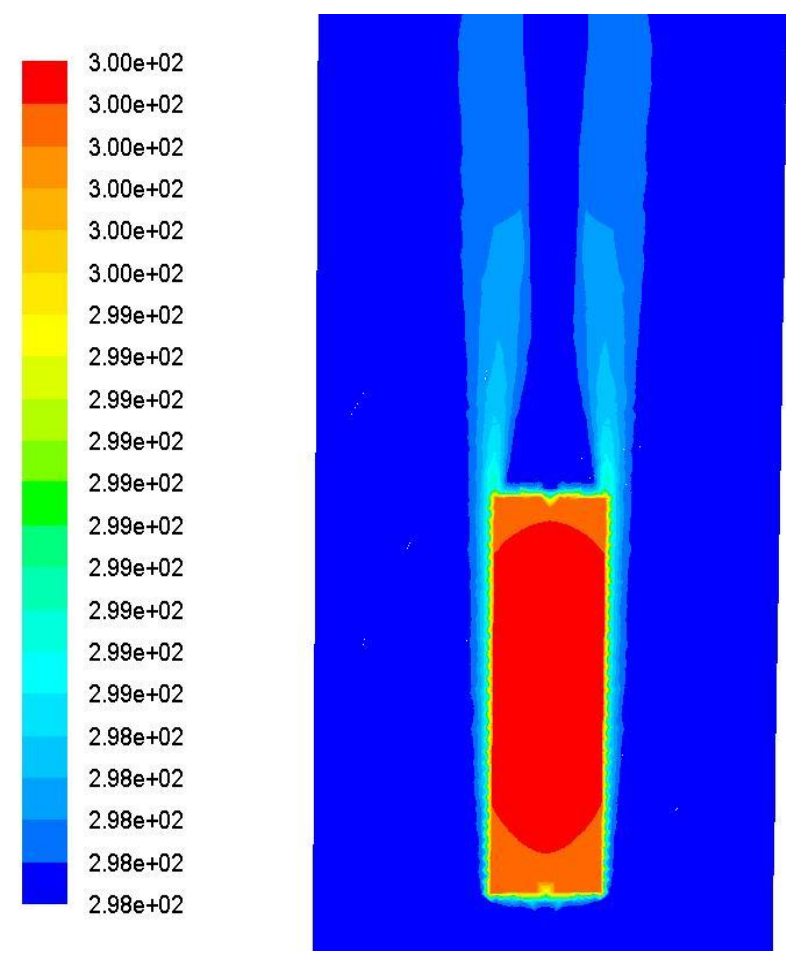

$$
\mathbf{R a}=\mathbf{1 0}^{8}
$$

Fig. (3): Temperature contours at different Ra for the case of vertical position

Figure 3 shows the temperature contours at various $\mathrm{Ra}$ for the case of the cylinder being at vertical position. From this figure it can be seen that by increasing $\mathrm{Ra}$ the thermal plume (region of high temperature) around the cylinder becomes thinner. This can be attributed to the fact that at $\mathrm{Ra}$ becomes lower the thermal boundary layer becomes thicker, and hence the thermal plume around the cylinder becomes thicker. As Ra becomes higher the flow around the cylinder becomes higher and the thermal plume becomes thinner. Fig.4 shows the flow field around the vertical cylinder at various $\mathrm{Ra}$ ranging from $6 \times 10^{4}$ to $10^{8}$. As seen from this figure, the fluid nearby the side of the cylinder rises towards upward direction. There are two wake regions: the first is directly around the bottom of the cylinder, where the flow coming from the colder fluid region and travelling downward to replace the hotter fluid adjacent to the cylinder at its lower part, changing direction from downward to upward as it becomes hotter. Whereas the second wake region is directly at the top of the cylinder, as the rising fluid leaving the side of the cylinder at its top end becomes closer and the velocity increases as the flow area decreases, hence a wake region is generated directly above the center region of the top of the cylinder. The diameter of the plume at maximum velocity region is high for low $\mathrm{Ra}$ and becomes smaller as $\mathrm{Ra}$ decreases. The value of the maximum velocity at $\mathrm{Ra}=10^{8}$ is about 24 times the value at $\mathrm{Ra}=$ $6 \times 10^{4}$. Figure 5 shows the effect of $\mathrm{Ra}$ on average $\mathrm{Nu}$ for various values of tilting angle. From this figure it can be shown that average $\mathrm{Nu}$ increases with the increase in $\mathrm{Ra}$, and this increase is more pronounced at higher values of $\mathrm{Ra}$ for all of the cases of tilting angle. By varying the tilting angle from vertical position, the average $\mathrm{Nu}$ increases until the tilting angle is $45^{\circ}$ (half the way between vertical and horizontal position, then by increasing the tilting angle furthermore the average $\mathrm{Nu}$ starts to decrease. 

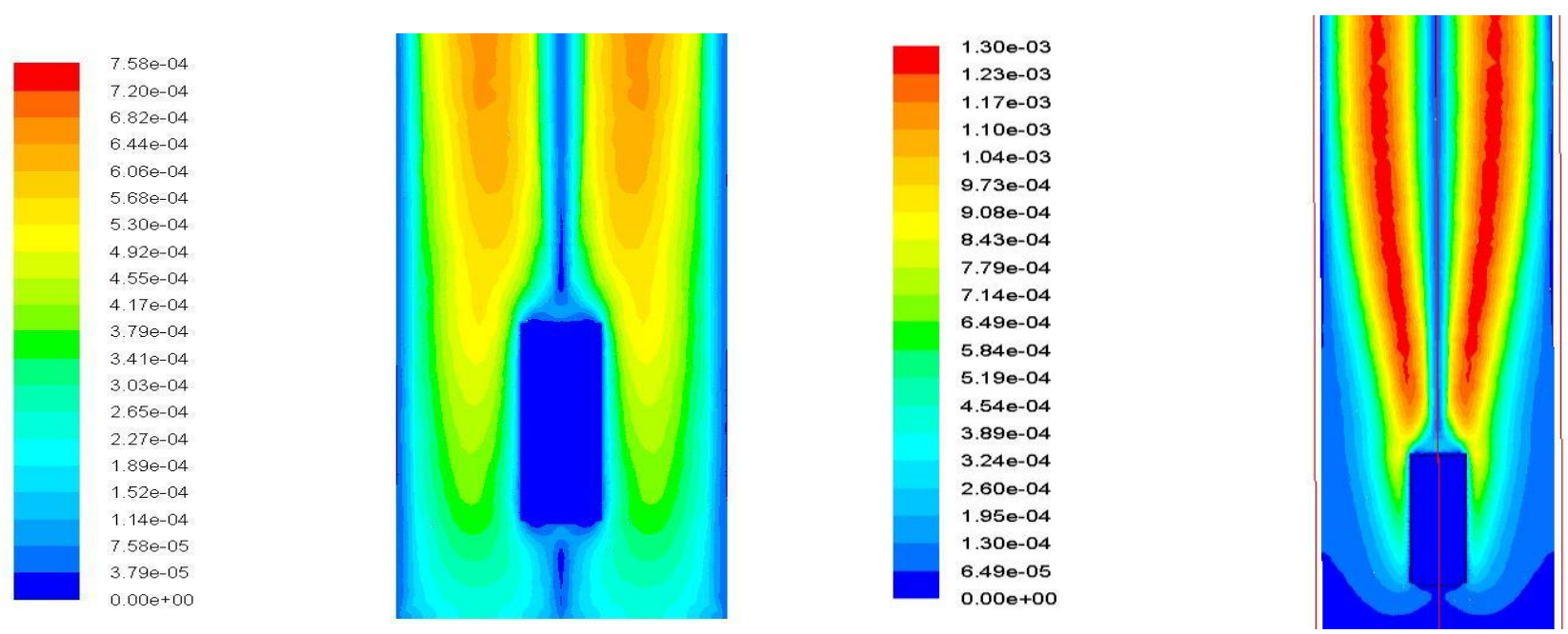

$$
\mathbf{R a}=6 \times 10^{4}
$$
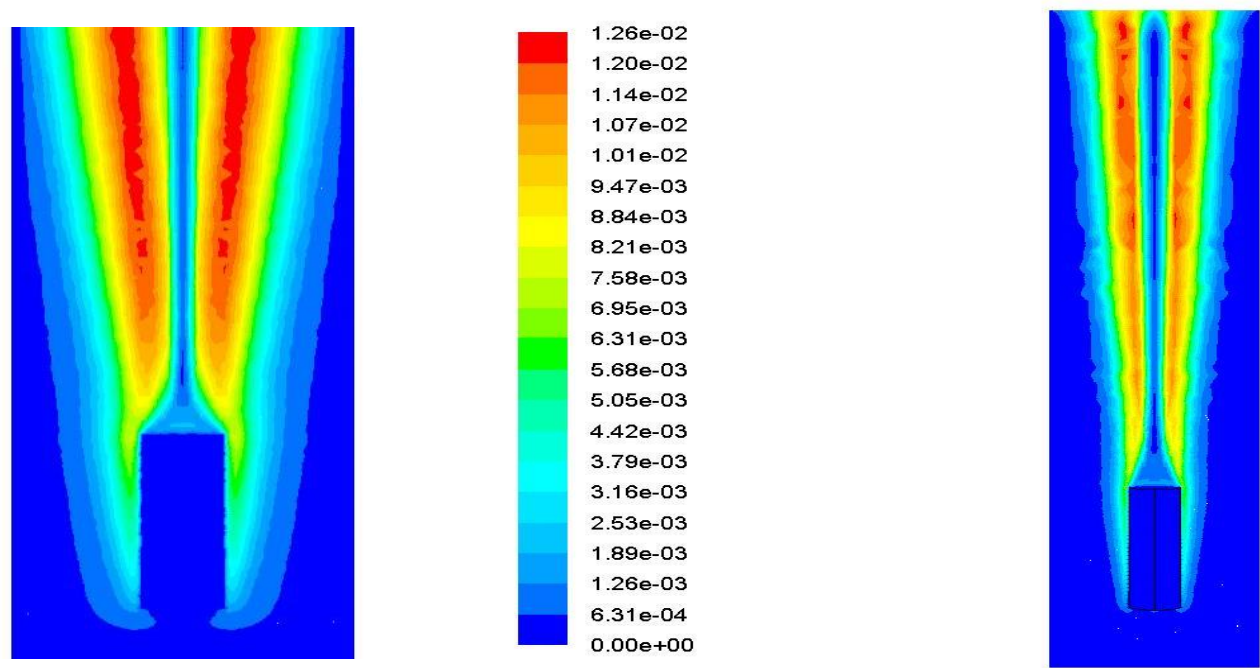

$$
\mathbf{R a}=4 \times 10^{6}
$$$$
\mathbf{R a}=3 \times 10^{\prime}
$$
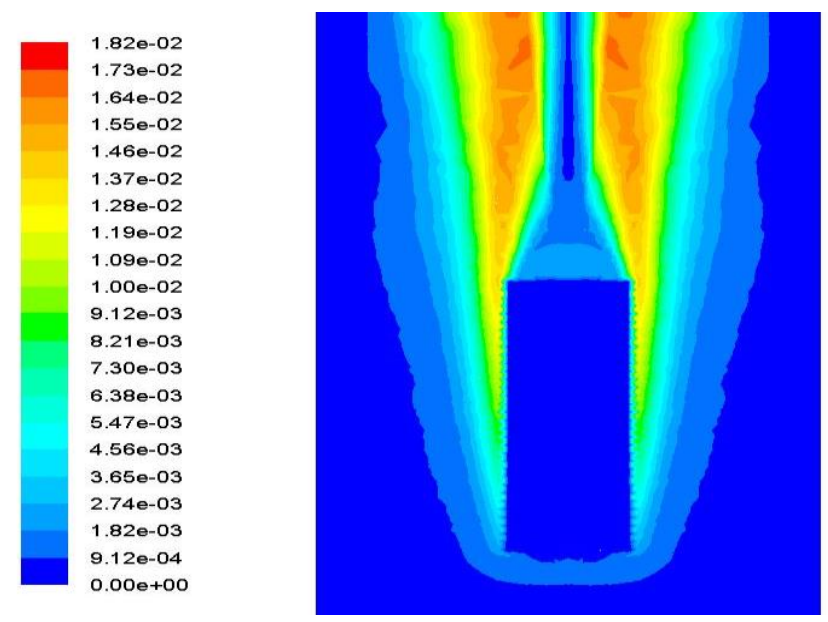

$\mathbf{R a}=10^{8}$

Fig. (4): Velocity contours at different Ra for the case of vertical position 


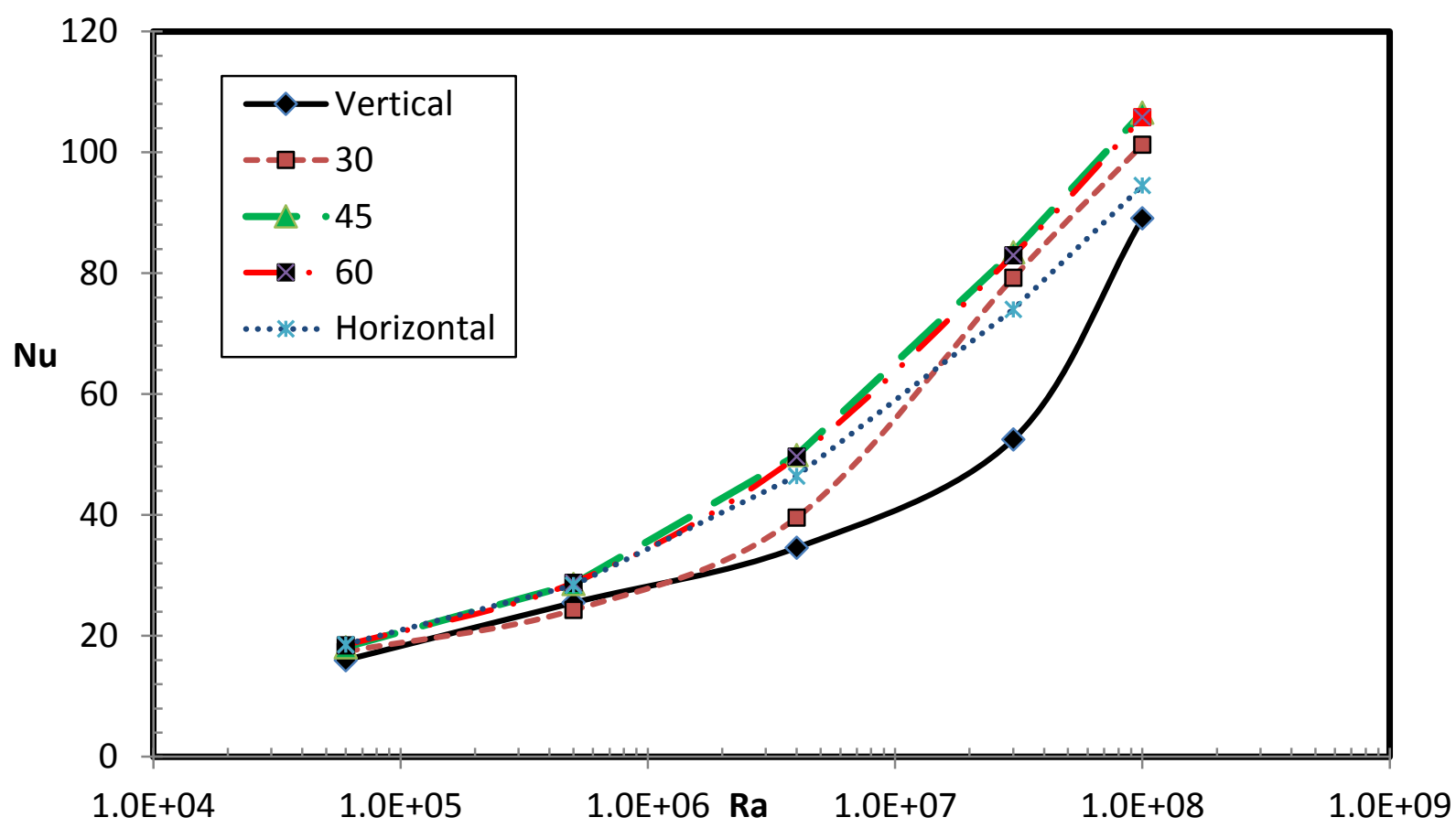

Fig. (5): Variation of average $\mathrm{Nu}$ with $\mathrm{Ra}$ at different tilting angles

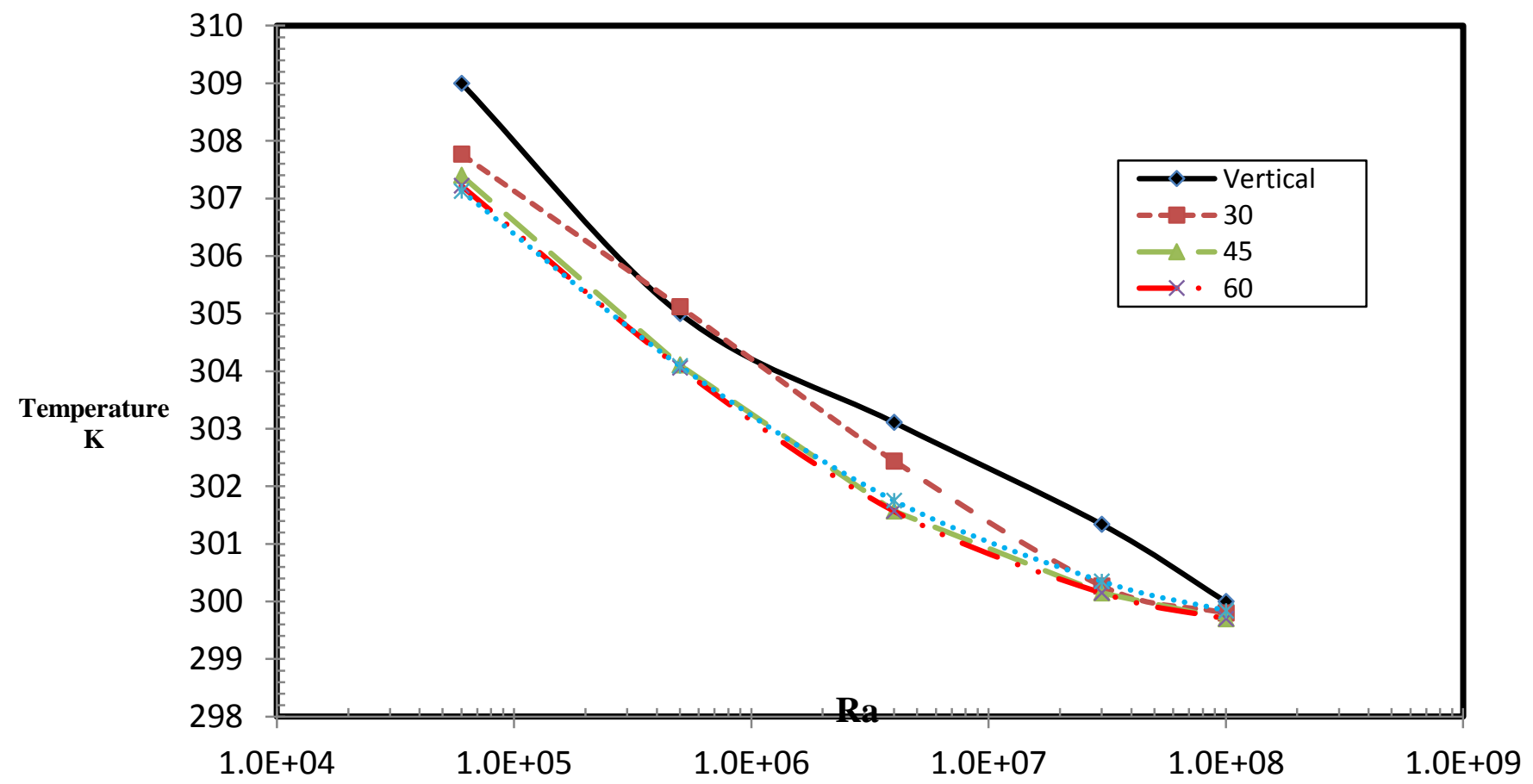

Fig. (6): Variation of average surface temperature with Ra at different tilting angles

Figure 6 shows the variation of average surface temperature of the cylinder with $\mathrm{Ra}$ at different tilting angles. As shown in this figure, the average surface temperature decreases with the increase in Ra for all of the cases of tilting angle. As the tilting angle varies from the vertical position, the average surface temperature shows reverse trend w.r.t the trend of $\mathrm{Nu}$ which has been previously discussed, i.e the temperature decreases until the tilting angle is $45^{\circ}$. Further increase of the tilting angle after $45^{\circ}$ seems to have no significant effect on the average surface temperature, but the decrease in $\mathrm{Nu}$ which occurs at greater tilting angle than $45^{\circ}$ results from the fact that the surface heat flux decreases for tilting angles greater than $45^{\circ}$. 


\subsection{Effect of tilting angle}
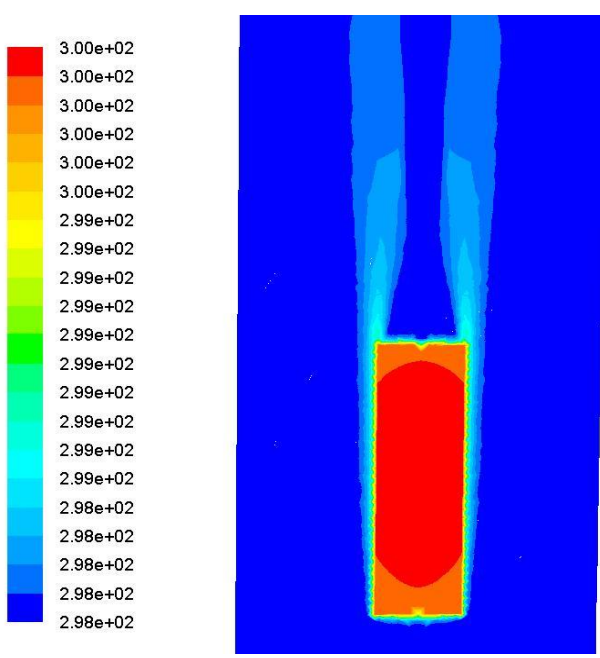

Vertical
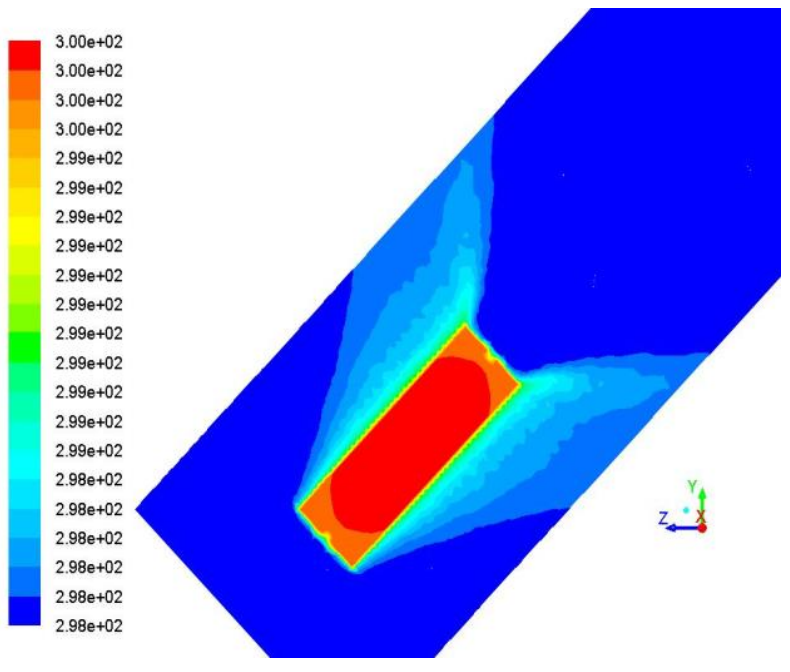

$45^{\circ}$

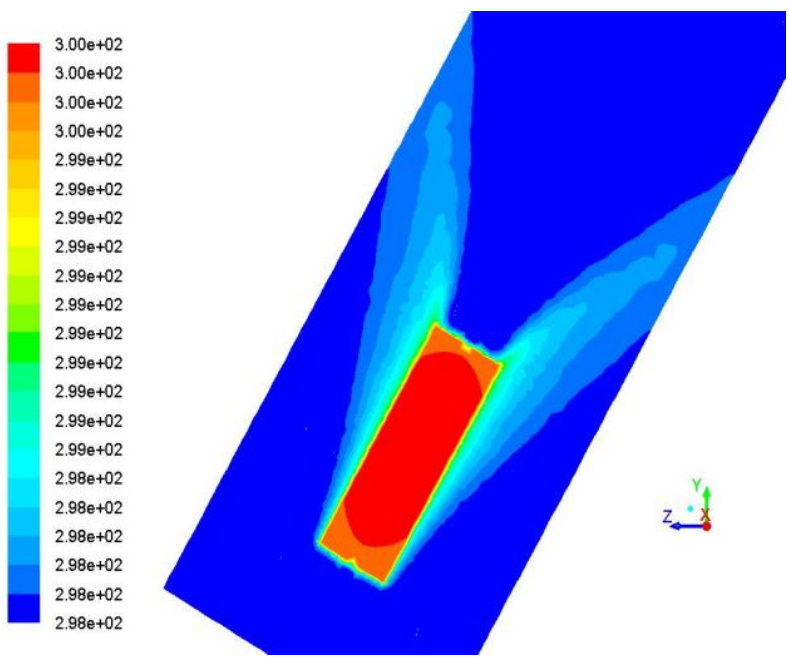

$30^{\circ}$

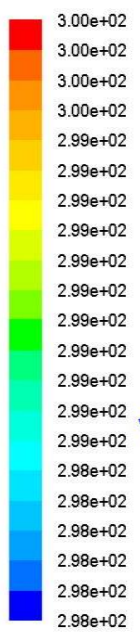

$2.98 \mathrm{e}+02$

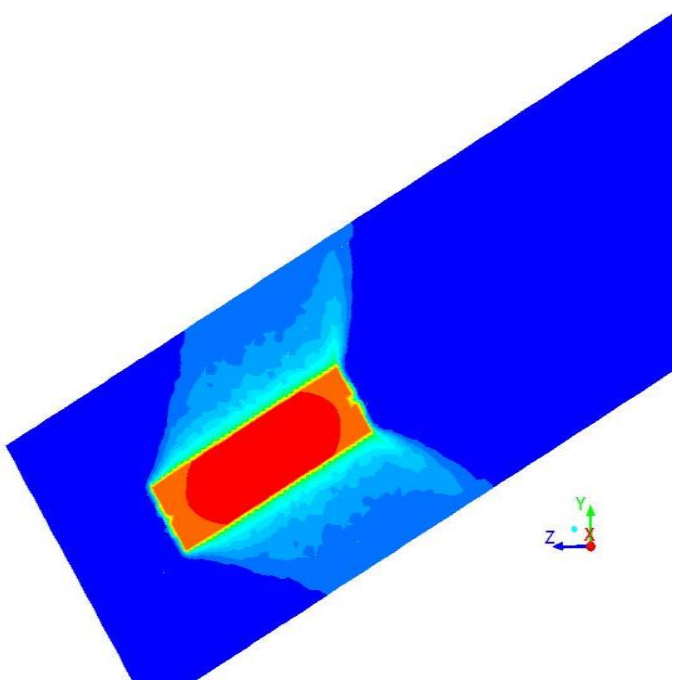

$60^{\circ}$

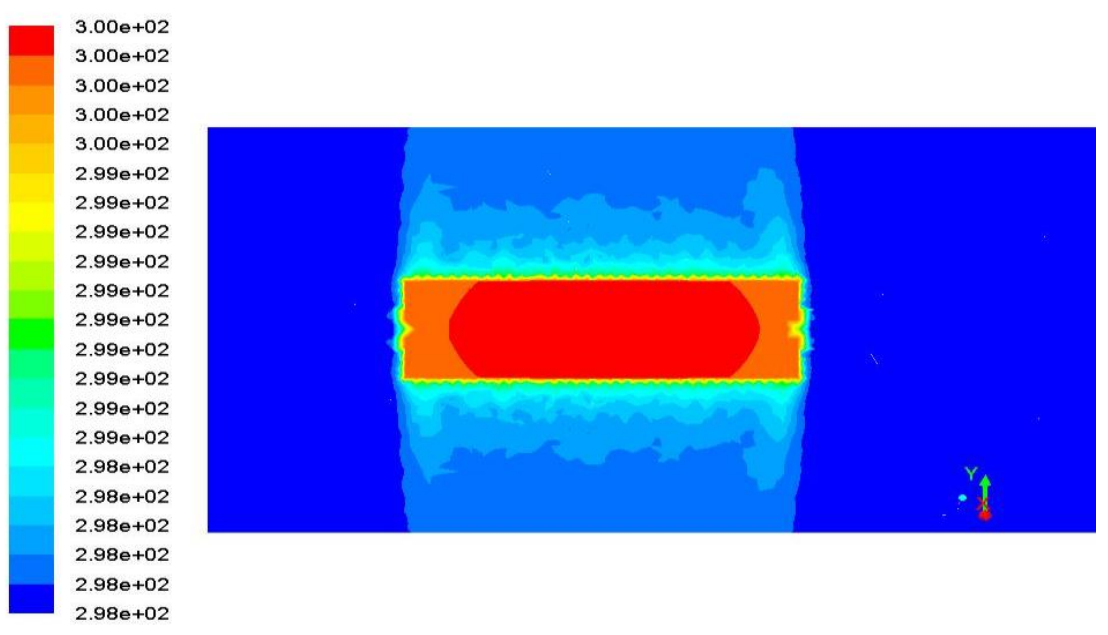

\section{Horizontal}

Fig. (7): temperature contours at different tilting angles for the case of $\mathrm{Ra}=10^{8}$ 
Figure 7 shows the temperature contours at different tilting angles for the case of $\mathrm{Ra}=10^{8}$. From this figure it can be shown that in all cases the maximum temperature region is at the center of the cylinder surface and the temperature becomes lower towards the two ends of the cylinder. In the water region, the temperature contour has two branches starting from the two sides of the cylinder. These two branches are closed to each other for
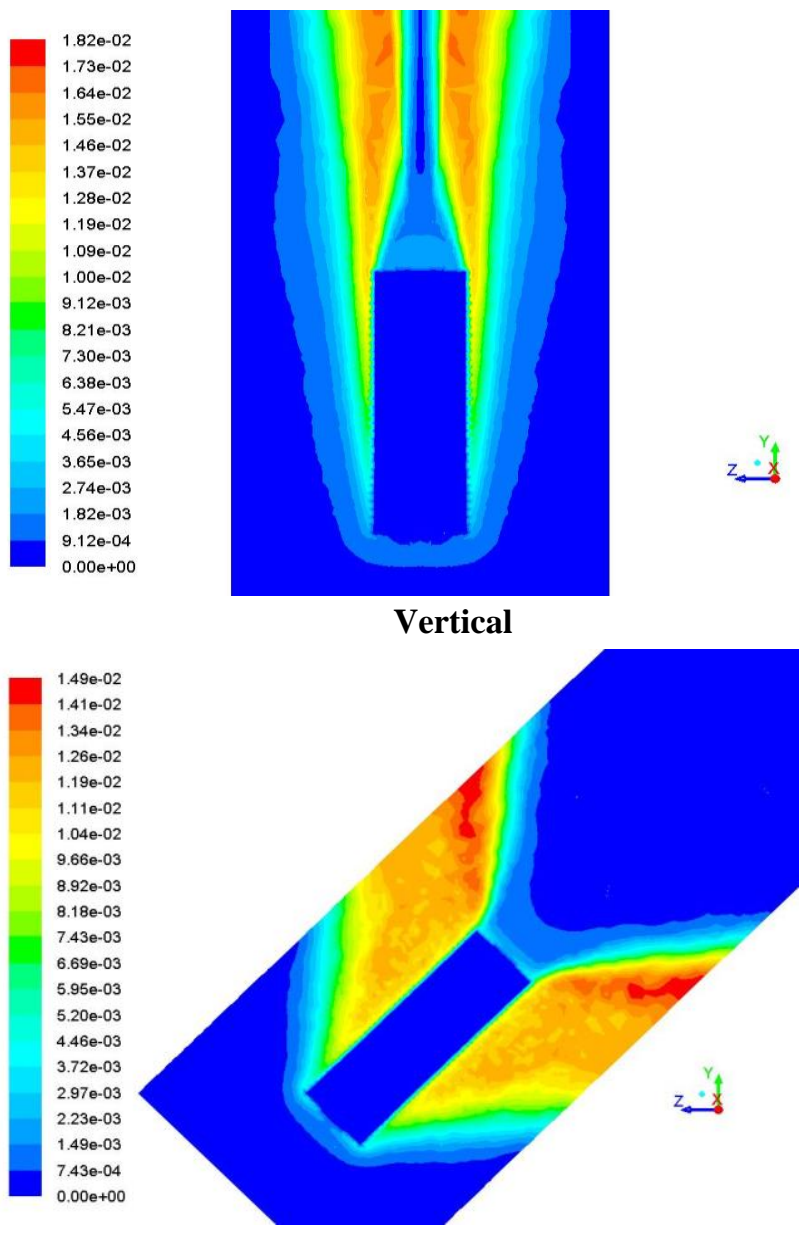

$45^{\circ}$ the case of vertical position forming a V shape and the divergence of this $\mathrm{V}$ shape increases as the tilting angle increases and finally the two branches become completely separate for the case of horizontal position. The temperature values differ slightly with the change in the tilting angle for the same $\mathrm{Ra}$ and heat generated, whereas the temperature strongly depends on $\mathrm{Ra}$ as discussed before.
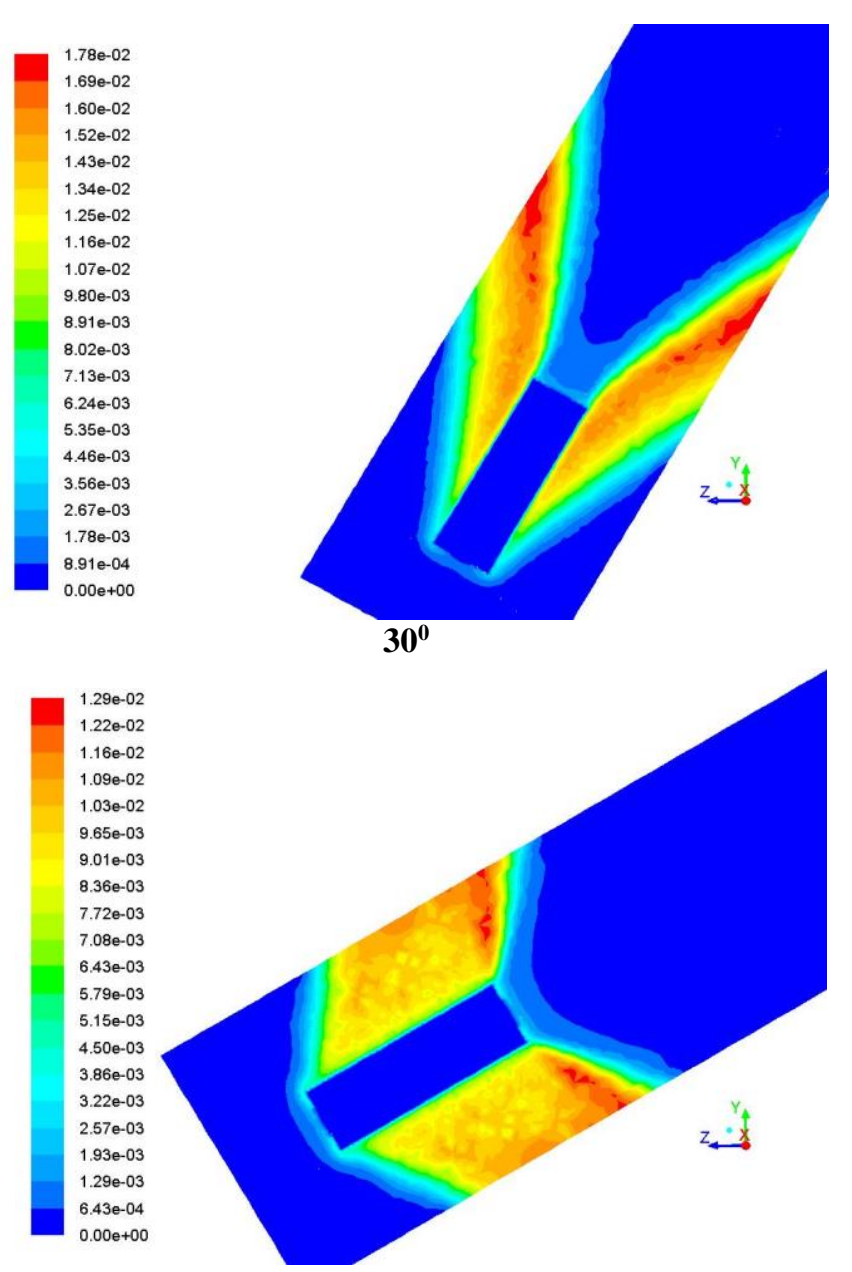

60

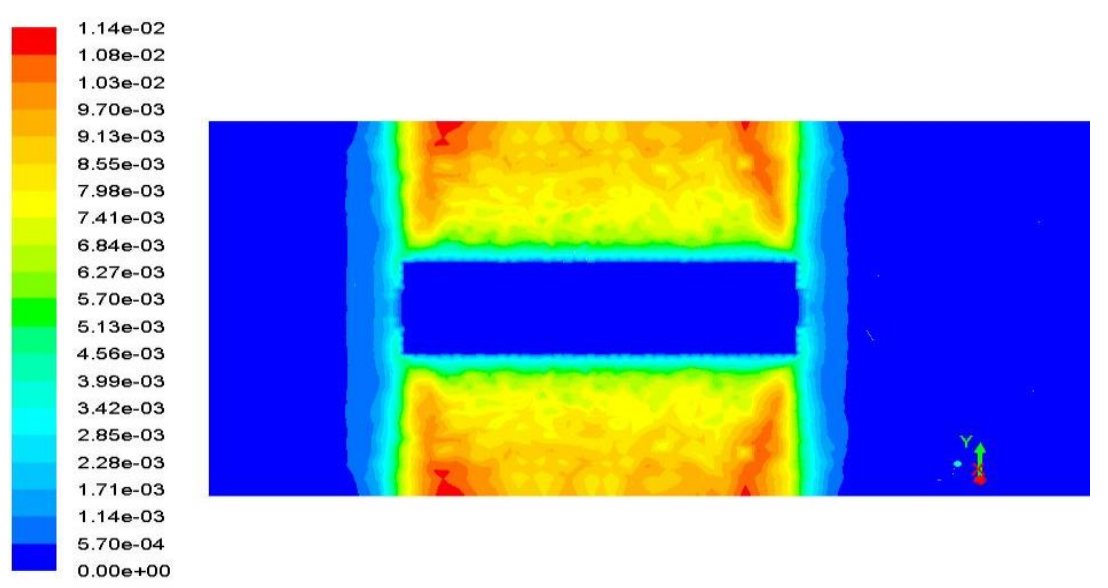

Horizontal

Fig. (8): Velocity contours at different tilting angles for the case of $\mathbf{R a}=10^{8}$ 
Figure 8 shows the flow field (velocity contours) around the cylinder at different tilting angle ranging from $0^{\circ}$ (which corresponds to vertical position) to $90^{\circ}$ (which corresponds to horizontal position) for the case of $\mathrm{Ra}=10^{8}$. From this figure it can be shown that for all cases flow separation occurs due to the stagnation which occurs at the lower part of the cylinder body. As for the two wake regions which are previously discussed in Fig.4, the one which is directly around the bottom of the cylinder still exists. After leaving the cylinder at its top end, the two branches of the fluid leaving the two sides of the cylinder comes closer for the case of vertical position. Whereas by tilting the cylinder from vertical position, these two branches diverges, and this divergence increase with the increase in tilting angle from the vertical position, and the maximum value of the flow velocity decreases as well.
Figure 9 shows the variation of $\mathrm{Nu}$ with tilting angle at different values of $\mathrm{Ra}$. As shown from the figure, $\mathrm{Nu}$ increase with $\mathrm{Ra}$ at the same tilting angle as mentioned before. For a certain value of $\mathrm{Ra}$, the $\mathrm{Nu}$ increases with the increase in tilting angle until a value of $45^{\circ}$ and then starts to decrease. But this trend is more pronounced for higher values of Ra. Fig. 10 shows the variation of average surface temperature with tilting angle at different values of Ra. Nearly a reverse trend to the trend of $\mathrm{Nu}$ is shown in this figure. I.e the average surface temperature decreases with the increase in $\mathrm{Ra}$ at the same tilting angle. For the same Ra, the temperature decreases by increasing the tilting angle until reaching $45^{\circ}$ and then it starts to increase by further increase in the tilting angle. The increase in the average surface temperature for tilting angles greater than $45^{\circ}$ is more pronounced for higher Ra. For $\mathrm{Ra}$ values of E4, E5, the temperature is nearly constant for tilting angles greater than $45^{\circ}$.

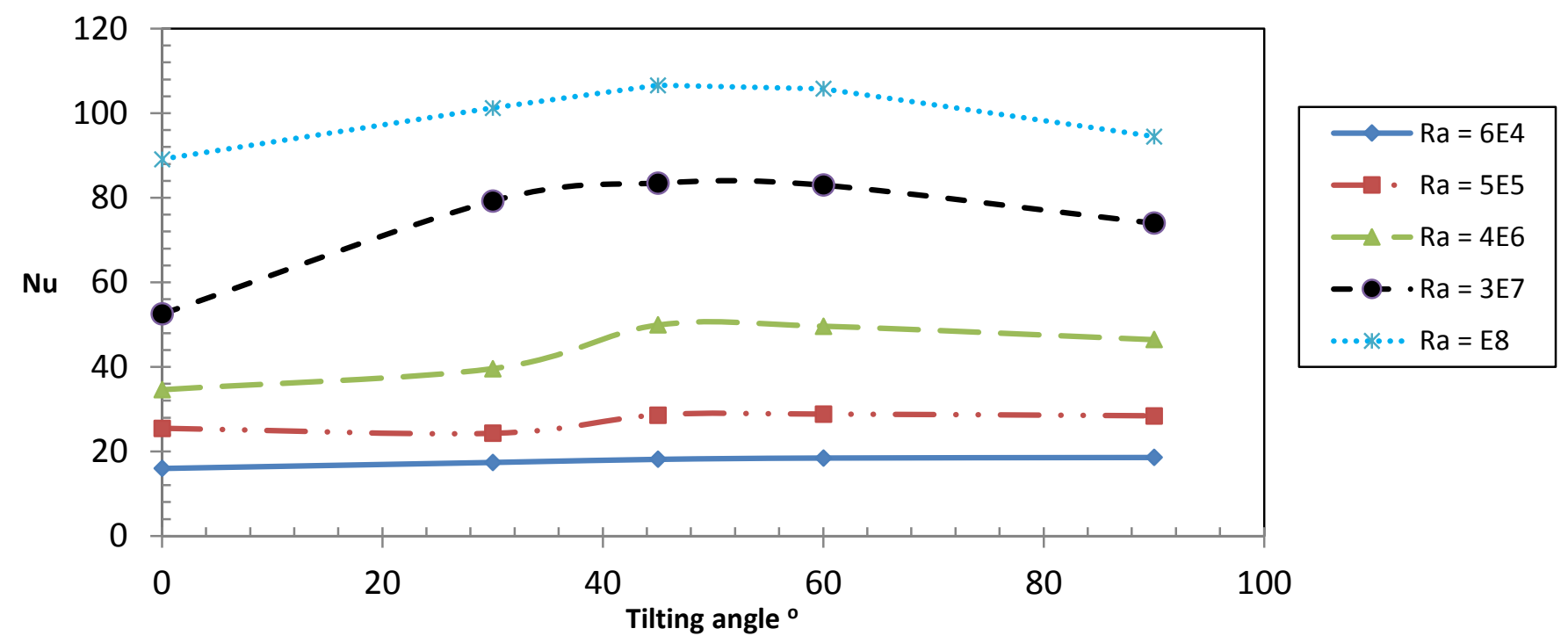

Fig. (9): Variation of Nu with tilting angles at different Ra

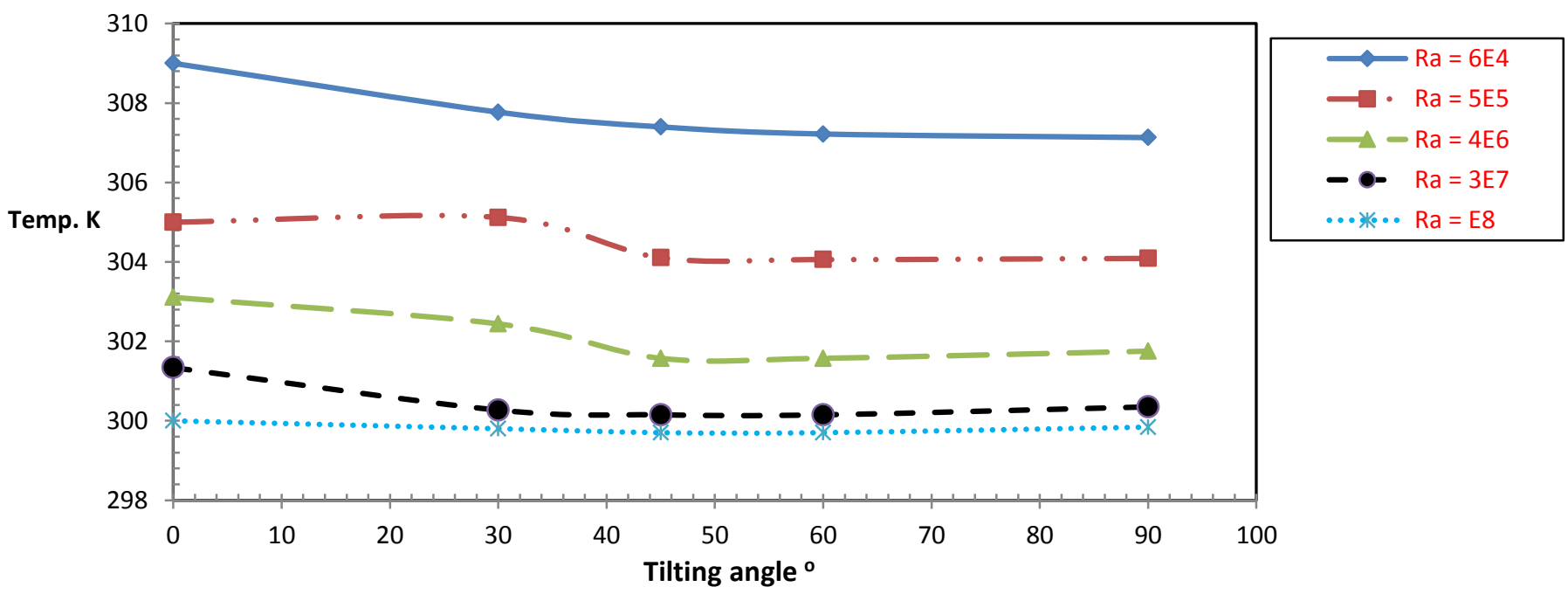

Fig. (10): Variation of average surface temperature with tilting angle at different Ra 


\subsection{Development of a single correlation for all inclination angles}

A single correlation relating $\mathrm{Nu}$ with $\mathrm{Ra}$ irrespective of the inclination angle can be developed using the characteristic length proposed by Neetu Rani et al. [16]. This characteristic length is:

$$
\mathrm{L}_{\mathrm{c}}=\left[\frac{L D}{L / D \cos \theta+D / L \sin \theta}\right]^{1 / 2}
$$

Where: $\theta$ is the angel from the horizontal position.

All of the data relating $\mathrm{Nu}$ with $\mathrm{Ra}$ at different inclination angle were fitted as shown in Fig.11 and a correlation in the form $\mathrm{Nu}=\mathrm{a} \mathrm{Ra}{ }^{\mathrm{b}}$ was tested. The best fit equation for the data trend line was:

$\mathrm{Nu}=0.978 \mathrm{Ra}^{0.238}$

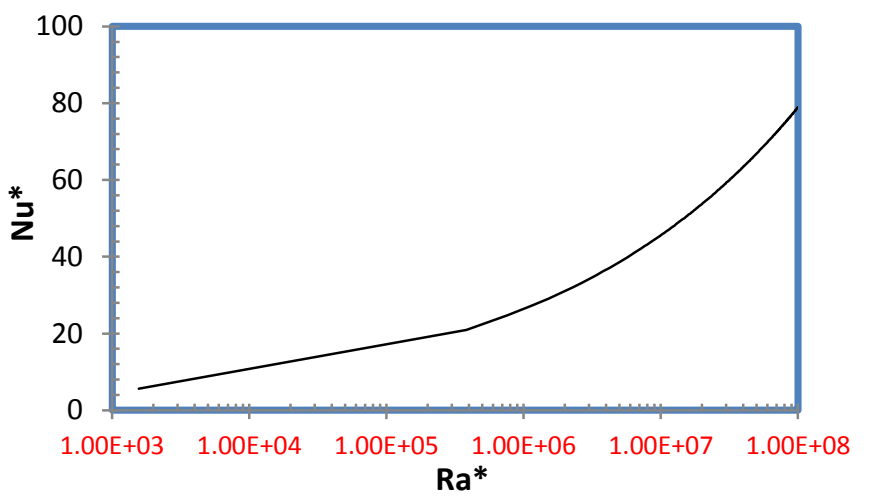

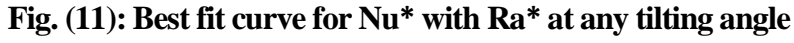

\section{CONCLUSIONS}

Analytical analysis using Ansys 15.0- Fluent computer code. of natural convection heat transfer from a cylinder suspended in water at different tilting angle has been analyzed numerically by varying the $\mathrm{Ra}$ in laminar regime $\left(10^{4} \leq \mathrm{Ra} \leq\right.$ $\left.10^{8}\right)$. The numerical analysis is carried out at different tilting angles in the range from $0^{\circ}$ to $90^{\circ}$ from vertical position. The results obtained can be summarized as follow:

1- By increasing $\mathrm{Ra}$, the average $\mathrm{Nu}$ as well as flow velocity increase while the average surface temperature decreases and the thermal and velocity plume become thinner for all cases.

2- By increasing the tilting angle from the vertical position, the average $\mathrm{Nu}$ increases whereas the average surface temperature decreases until a tilting angle of $45^{\circ}$. Further increase in the tilting angle results in decrease in the average $\mathrm{Nu}$, whereas average surface temperature increases for high values of Ra, while it nearly remains constant for relatively low values of Ra. Whereas the thermal and velocity plumes have two branches of $\mathrm{V}$ shape which diverge by increasing the tilting angle.

3- The data relating $\mathrm{Nu}$ with $\mathrm{Ra}$ at any inclination angel can be correlated with a single correlation using a previously proposed characteristic length which depends on the inclination angle.

\section{REFERENCES}

[1] Swastik Acharya, Sumit Agrawal, and Sukanta K Dash, Numerical analysis of natural convection heat transfer from a vertical hollow cylinder suspended in air, Journal of Heat Transfer, November 2017.

[2] Churchill SW and Chu HHS, Correlating equations for laminar free convection from a horizontal cylinder, Int. J. Heat Mass Transfer, vol. 18; pp1049-53, 1975.

[3] Churchill SW, A comprehensive correlating equation for laminar, assisting, forced and free convection, AICHE J., vol. 23; pp 10-6, 1973.

[4] Gebhart B, Jaluria Y, Mahajan RI, Sammakia B. , Buoyancy -inducted flows and Transport, New York, Hemisphere Publishing Corporation, 1988.

[5] Ozisik MN, Heat Transfer a Basic Approach, Singapore: McGraw-Hill Book Company, 1985.

[6] Holman JP, Heat Transfer.tenthed . New York; McGraw -Hill Higher Education 2010.

[7] LeFevre EJ, Ede AJ, Laminar Free Convection From the Outer Surface of a Vertical Circular Cylinder,In;Proc.9th Int. Congr. Appl. Mech, pp.175-83, 1956.

[8] Fujii T, Uehara H., Laminar Natural Convection Heat Transfer From the Outer Surface of a Vertical Cylinder, Int.J.Heat Mass Transfer., vol. 13; pp 607-15, 1970.

[9] Acharya. S and Dash S. K, Natural Convection Heat Transfer from a Short or Long, Solid or Hollow Horizontal Cylinder Suspended in Air or Placed on Ground, ASME J Heat Transfer; vol. 139 (7); pp 072501, 2017.

[10] Acharya. S and Dash S. K, Natural Convection Heat Transfer From perforated Hollow Cylinder with Inline and Staggered Holes, ASME J Heat Transfer., doi: 10.1115/1.4037875, 2017.

[11] L. Davidson, D.G. Bahraini, R.Karlsson,Natural Convection Heat Transfer In Vertical Shell And Tube, Chalmers University Of Technology, Goteborg, Sweden, December 2002.

[12] L.J.Crane, Natural Convection On Vertical Cylinder at Very High Prandtl Numbers, Journal Of Engineering Mathematics,10(2), 115-124),1976.

[13] C. O. Popiel, Free convection heat transfer from vertical slender cylinder, Heat Transfer Engineering, 29(6),521536, ),2008.

[14] A. Shiri, William K.George, Experimental Study of the Near Wall Region of a Natural Convection Driven Flow Next to a Vertical Cylinder, Springer Proceedings In Physics, 141, 2012,287-291.

[15] Minkowycz W, Sparrow E, Local Non Similar Solutions for Natural Convection on a Vertical Cylinder .J. Heat Transf., vol. 96; pp178-83, 1974.

[16] Neetu Rani, Hema Setia, Marut Dutt. R.K. Wanchoo, Natural Convection Heat Transfer from Inclined Cylinders: A Unified Correlation, International Journal of Physical and Mathematical Sciences, Vol 8, No.1, 2014. 